\title{
On the relations between proton influx and D-region electron densities during the polar-cap absorption event of 28-29 October 2003
}

\author{
J. K. Hargreaves ${ }^{1,2}$ and M. J. Birch ${ }^{2,3}$ \\ ${ }^{1}$ Department of Communication Systems, University of Lancaster, Bailrigg, Lancaster LA1 4WA, UK \\ ${ }^{2}$ Centre for Astrophysics, University of Central Lancashire, Preston PR1 2HE, UK \\ ${ }^{3}$ Department of Computing, University of Central Lancashire, Preston PR1 2HE, UK
}

Received: 8 April 2005 - Revised: 17 August 2005 - Accepted: 16 September 2005 - Published: 30 November 2005

\begin{abstract}
Observations by incoherent-scatter radar have been applied to explore relationships between the fluxes of incident protons and the resulting D-region electron densities during a polar-cap radio-absorption event. Using proton flux data from a GOES geosynchronous satellite, the energy band having the greatest influence at a selected height is estimated by a process of trial and error, and empirical relationships are defined. The height profiles of the effective recombination coefficient are determined for day and night, and the transition over the evening twilight is investigated for the height range $60-70 \mathrm{~km}$.

The results show that the day-night change is confined to heights below $80 \mathrm{~km}$, night-time values at the lower levels being consistent with a balance between negative ions and electrons controlled by 3-body attachment and collisional detachment. The daytime results confirm that, contrary to the prediction of some chemical models, a square-law continuity equation may be strictly applied. It is confirmed that, as previously reported, the timing of the sunset change varies with altitude.
\end{abstract}

Keywords. Ionosphere (Ion chemistry and composition; Particle precipitation; Polar ionosphere)

\section{Introduction}

It is 45 years since D. K. Bailey identified solar protons of $\mathrm{MeV}$ energies as the cause of excess D-region ionization over the polar caps following some major solar disturbances (Bailey, 1959). An important step in the argument was to demonstrate that the relation between proton flux and D-region electron density could be explained using reasonable mesospheric parameters and appropriate reaction rates

Correspondence to: J. K. Hargreaves

(j.hargreaves@lancaster.ac.uk) for the essential chemistry governing the ionic reactions in the mesosphere. Bailey's work was based on forward-scatter communication circuits, but most of the early observations of these events were made with riometers observing the absorption of cosmic radio noise (Hultqvist, 1969; Reid, 1974). The riometer measures the integrated effect through the whole absorbing layer, and when observed in this way the event is known as a polar-cap absorption event (PCA). Rocket flights can provide the profile of electron density through the region, though only twice during a single flight. The body of data has, however, been considerably extended in recent years by incoherent-scatter radar (for example Reagan and Watt, 1976; Hargreaves et al., 1987; Collis and Rietveld, 1990). Radar can provide continuous measurements, though there are limits to the sensitivity, particularly at the lower altitudes. One practical problem is getting the radar operating for the event if a run has not already been scheduled; in particular, the start of the event has rarely (if ever) been observed by incoherent scatter radar. Satellite-borne detectors now provide continuous monitoring of the proton fluxes within the magnetosphere.

In relating the proton flux to the electron density the greatest element of uncertainty is the "effective recombination coefficient" for D-region electrons, $\alpha_{e f f}$ in the equation

$q=\alpha_{e f f} N_{e}^{2}$

$\mathrm{q}$ being the electron production rate and $\mathrm{N}_{e}$ the electron density. The production rate may be computed from the proton flux using the basic physics of ionization in air and an atmospheric model. Thus, observations of electron density and proton flux during these events have been applied to determining values of $\alpha_{e f f}$ experimentally. Unfortunately the values so determined vary widely (Penman et al., 1979; Gledhill, 1986). Further determinations are therefore of interest, and the event of 28-29 October 2003 provides one such opportunity since the EISCAT radar in Scandinavia was 


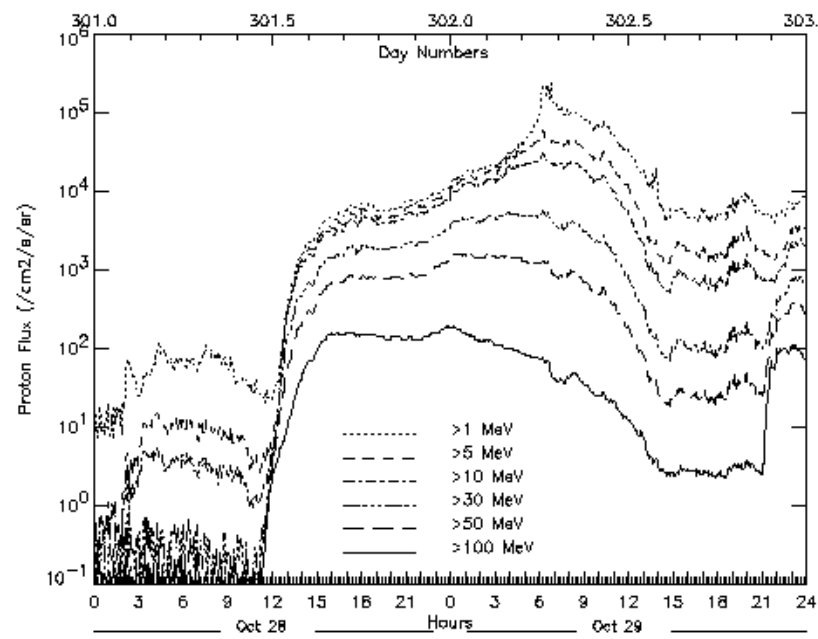

Fig. 1. Proton fluxes exceeding 100, 50, 30, 10, 5, and $1 \mathrm{MeV}$, GOES-11, 28-29 October 2003.

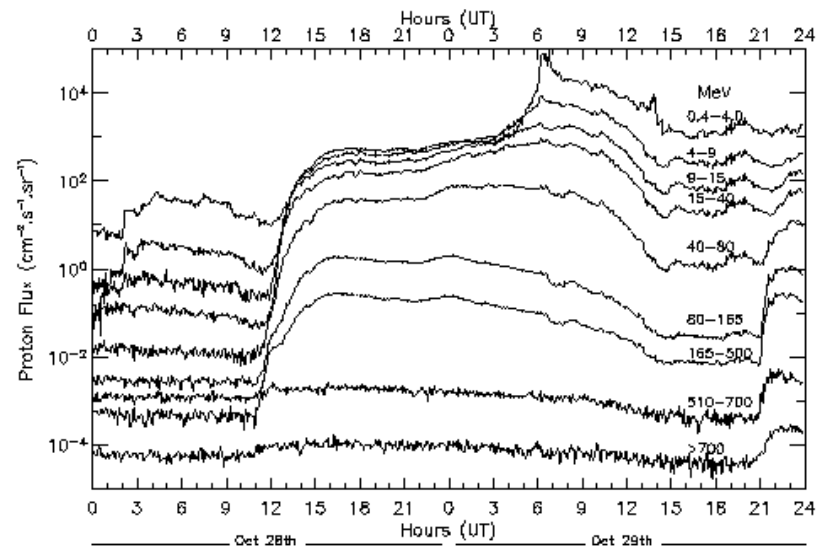

Fig. 2. Proton fluxes in 9 energy bands, GOES-11, 28-29 October 2003.

operating and the proton fluxes at geosynchronous orbit were monitored on GOES satellites.

Some authors have presented empirical relationships between the proton flux in a selected energy band and the total radio absorption or the electron density at selected altitudes. We shall attempt this, also, for the event of October 2003.

\section{Observations and data}

On 28 October 2003 a proton flare (type X17/4B) occurred on the Sun, peaking at 11:10 UT. In terms of its X-ray emission it was one of the most intense flares of the present solar cycle. A coronal mass ejection (CME) was observed at 10:54 UT, and within the terrestrial magnetosphere the flux of energetic protons began to increase at 11:50 UT. This flux peaked at 00:15 UT on 29 October, and the event ended about 13:10 UT on 1 November.
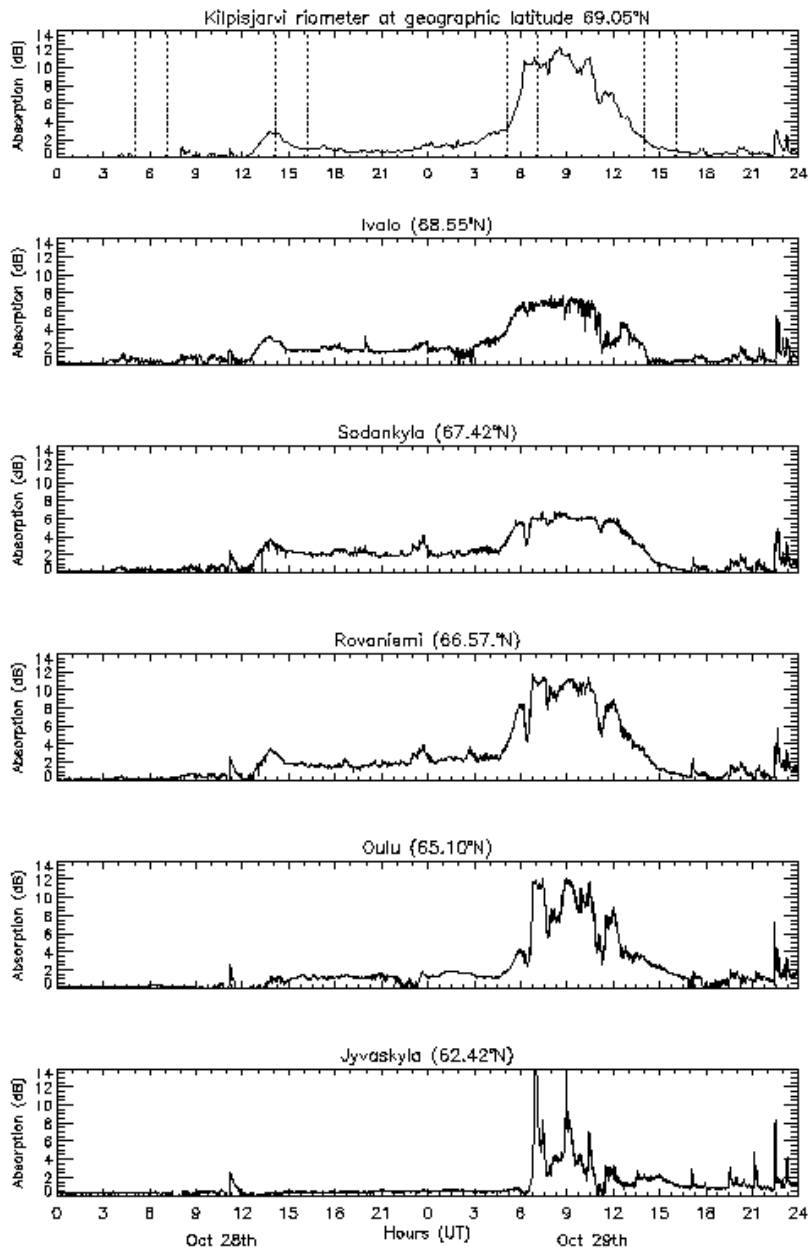

Fig. 3. Cosmic-noise absorption observed by riometers in Scandinavia, 28-29 October 2003, covering invariant latitudes 65.7, $64 \cdot 8,63 \cdot 7,62 \cdot 8,61 \cdot 2$, and $58.7^{\circ}$, respectively. The riometers at Rovaniemi and Jyvaskylä operate at $32.4 \mathrm{MHz}$, Kilpisjärvi at $38.2 \mathrm{MHz}$, and the others at $30.0 \mathrm{MHz}$. The vertical dotted lines show morning and evening twilight.

The fluxes of protons exceeding 1, 5, 10, 30, 50 and $100 \mathrm{MeV}$ observed by the geosynchronous satellite GOES11 (longitude $113^{\circ} \mathrm{W}$ ) are shown in Fig. 1. The increase in the flux at the lower energies in the morning of 29 October was associated with the arrival of the CME, and the sharp increase at the higher energies late that day was due to a second flare. Figure 2 shows how the flux varied in 9 energy channels covering the range from $0.4 \mathrm{MeV}$ to $>700 \mathrm{MeV}$.

Riometers in Scandinavia (Fig. 3) indicated absorption in the PCA rising to about $3.5 \mathrm{~dB}$ on 28 October and $12 \mathrm{~dB}$ on 29 October. The effect reduces towards the lower latitudes as far as Sodankylä, this marking the latitudinal cut-off which is characteristic of PCA (Bailey, 1964). The precipitation at lower latitudes shows the greater degree of irregularity typical of electron precipitation. The localised event at 11:18 UT was almost certainly the direct solar-flare effect (SFE) due to the arrival of solar X-rays. The increased level of irregularity at the lower latitudes will be due, at least in part, to variations in the cutoff latitude (Birch et al., 2005). 
The $224 \mathrm{MHz}$ EISCAT radar "the VHF radar" (Rishbeth and Williams, 1985) was operating at Tromso $\left(69.9^{\circ} \mathrm{N}\right.$, $19 \cdot 2^{\circ} \mathrm{E}$, invariant latitude $66 \cdot 3^{\circ}, \mathrm{L}=6 \cdot 2$ ) from $08: 15$ until 21:00 UT on 28 October and from 08:25 until 24:00 UT on 29 October. The range 60 to $140 \mathrm{~km}$ was covered with resolution $300 \mathrm{~m}$. The beam was either zenithal or directed $30^{\circ}$ to the zenith. The basic sampling interval was $1 \mathrm{~min}$. For the present study the data were averaged over $5 \mathrm{~min}$ in time and $1 \mathrm{~km}$ in height. Sample plots of electron density against time are shown in Figs. 4 and 5 for 28 and 29 October. The times of ground sunset and solar zenith angle $100^{\circ}$ are marked. Generally speaking, the day-night transition in PCA occurs between zenith angles $90^{\circ}$ and $100^{\circ}$. The gaps in these plots are due to glitches in the radar operation (that from 12:00 to 12:50 UT unfortunately concealing most of the initial phase of the PCA). Some enhancements, particularly at the greater heights, are probably the result of auroral electron precipitation.

There are similarities between the plots of absorption and electron density (Figs. 3-5), though the latter are much the noisier. However, exact tracking is not to be expected because the absorption is a height-integrated effect and also the contribution to absorption by a given electron density depends on the height. The most striking features of the absorption plots are the large increase and subsequence decrease on 29 October, the first occurring pre-sunrise but the second (which shows also in the electron density) being during the day and more related to the decline of proton flux after about 09:00 UT (Fig. 2). The relation between proton flux and electron density is explored in more detail in the next section.

\section{Empirical relations between proton flux and electron density}

Some studies of PCA events (e.g. Reid, 1970; Potemra, 1972) have compared the absorption measured with a riometer with the proton flux in some energy band as observed from a rocket or satellite above the atmosphere. These have provided empirical relationships which have some general application, for example in enabling the particle flux to be estimated from a measurement of the absorption, though they can only be approximate in the general context because of variations in the proton spectrum.

Collis and Rietveld (1990) derived empirical formulae relating the electron densities at 60,65 and $70 \mathrm{~km}$ to the integral proton fluxes above 10 and $30 \mathrm{MeV}$. We shall attempt a similar approach in the event of October 2003, but now comparing the particle flux in the bands shown in Fig. 2 with the electron densities at selected heights. Although the fluxes in these energy bands generally rise and fall together during the event, there are also variations of spectrum. Overall, the spectrum is usually more energetic at the beginning of a proton event and softens as the event proceeds. Superimposed may be other variations due to the commencement of a magnetic storm or a second emission from the Sun. The spectral
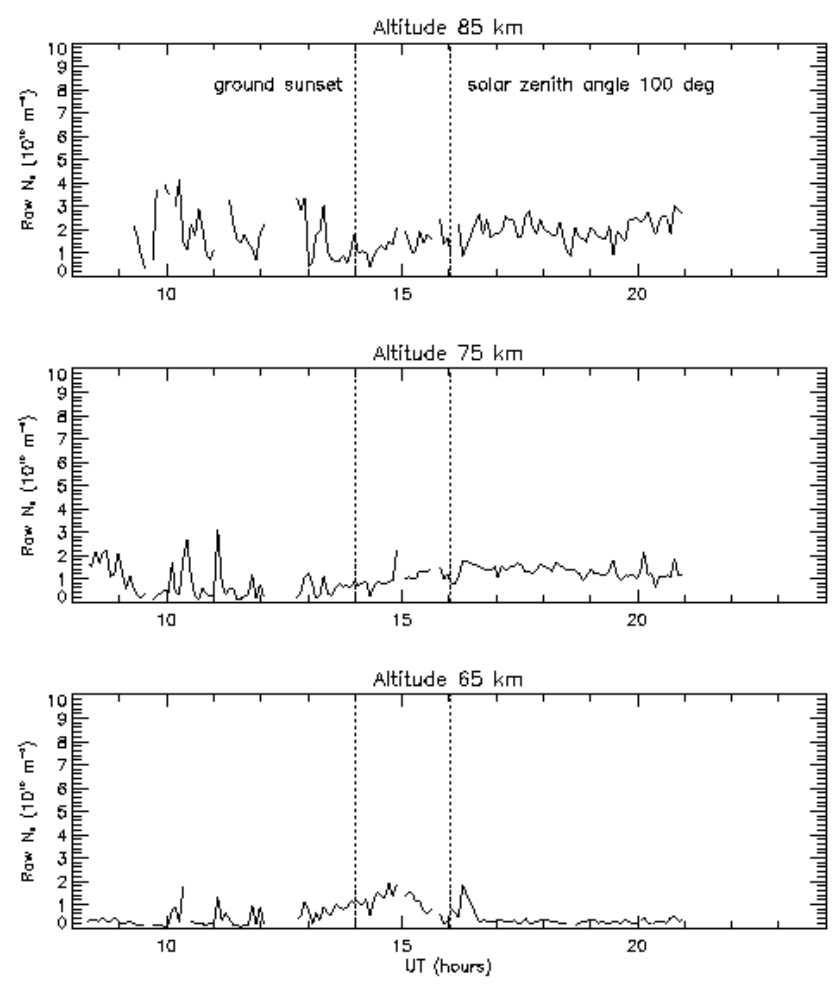

Fig. 4. Electron densities determined by the EISCAT VHF radar at Tromsö on 28 October. The radar operated from 08:15 to 24:00 UT.
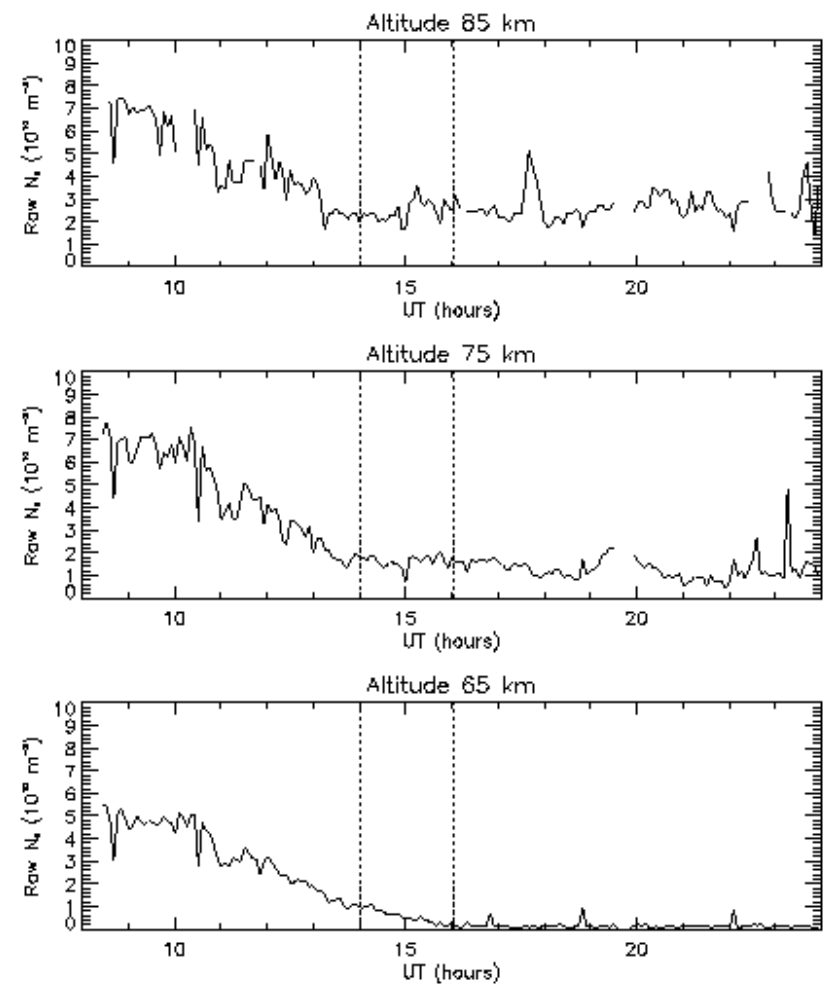

Fig. 5. As Fig. 4 but for 29 October. The radar operated from 08:25 to $08: 30 \mathrm{UT}$. 
Table 1. Relations between flux $\mathrm{F}\left(\mathrm{cm}^{-3} \mathrm{~s}^{-1} \mathrm{sr}^{-1}\right)$ in the most effective energy band and the electron density $\mathrm{N}_{e}\left(\mathrm{~cm}^{-3}\right)$ at selected altitudes.

\begin{tabular}{cccc}
\hline Altitude $(\mathrm{km})$ & $\begin{array}{c}\text { Most effective energy } \\
\text { band (MeV) }\end{array}$ & Relation & $\begin{array}{c}\text { Height of max. } \\
\text { production }(\mathrm{km})\end{array}$ \\
\hline 60 & $40-80$ & $N_{e}=7 \cdot 2.10^{9} \sqrt{F_{40-80}}$ & $48-37$ \\
65 & $9-15$ & $N_{e}=1 \cdot 5.10^{9} \sqrt{F_{9-15}}$ & $68-62$ \\
65 & $15-40$ & $N_{e}=2 \cdot 0.10^{9} \sqrt{F_{15-40}}$ & $62-48$ \\
70 & $4-9$ & $N_{e}=1 \cdot 0.10^{9} \sqrt{F_{4-9}}$ & $76-68$ \\
75 & $4-9$ & $N_{e}=1 \cdot 0.10^{9} \sqrt{F_{4-9}}$ & $76-68$ \\
80 & $4-9$ & $N_{e}=1 \cdot 2.10^{9} \sqrt{F_{4-9}}$ & $76-68$ \\
85 & $4-9$ & $N_{e}=1 \cdot 2.10^{9} \sqrt{F_{4-9}}$ & $76-68$ \\
90 & uncertain & & \\
\hline
\end{tabular}
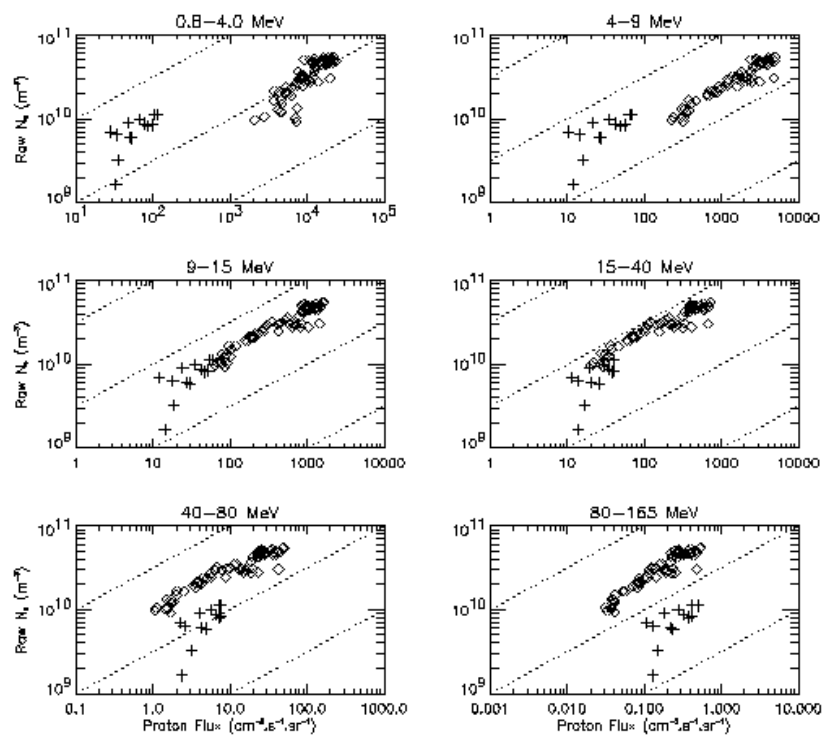

Fig. 6. Plots of electron density at $65 \mathrm{~km}$ against the proton flux in 6 of 9 energy bands, daytime, 28 and 29 October represented by crosses and diamonds respectively.

variations are what may enable us to find which energy band is most effective at a given height.

The observed electron density at 7 heights (from 60 to $90 \mathrm{~km}$ ) has been compared with the proton flux in the 9 energy bands of Fig. 2, separately for day and night (126 comparisons in all). The comparisons for $65 \mathrm{~km}$ by day are illustrated in Fig. 6. The dotted lines represent the reasonable assumption of a square-law relationship. In the daytime periods of this event both the fluxes and the spectrum differed significantly between 28 and 29 October and the plot with best continuity (by visual inspection) indicates which band is the main contributor to ionization at the height in question. Table 1 summarises the results for daytime, including empirical equations relating electron density to proton flux. These equations should be of general application to proton events other than this one. The heights most affected by the individual bands are consistent with the calculated heights of maximum production rate for protons in the atmosphere (Reid, 1974), bearing in mind that the rate of recombination decreases towards greater heights and that protons of a given energy ionize above their stopping height but not below it; both factors which tend to bias the effect upward.

This approach does not work well for the night periods. At the lower heights the electron densities are smaller by night than by day and those values are more scattered due to the sensitivity limitations of the radar. Also, it so happened that the flux did not vary much between or during the night periods of 28 and 29 October, so no clear correlation could be established even at the greater heights. It was noted, however, that the rather blobby distributions obtained for night would fit onto the linear distributions obtained for day at $80 \mathrm{~km}$ and above, which suggests that the same law may apply by day and by night at those heights.

\section{Effective recombination coefficients}

\subsection{Determinations using raw electron densities}

From the proton fluxes, production rates were calculated every $5 \mathrm{~km}$ from 60 to $90 \mathrm{~km}$, using the method of Reid (Reid, 1986; Reid et al., 1991). This method takes the integral proton fluxes from GOES (as in Fig. 1), calculates the ionization rate as a function of height for particles of various energy, and then sums over all energies and all pitch angles. The production rates at 55, 65, 75 and $85 \mathrm{~km}$ are illustrated in Fig. 7.

We note that before the arrival of the shock at about 06:05 on 29 October the ion production rate increases with decreasing altitude. It actually maximised at $50-55 \mathrm{~km}$, which is below the range of heights covered by the radar. At the shock the spectrum softened and thereafter the production rate was more uniform with height, being within a factor of two over $60-90 \mathrm{~km}$.

Figure 8 shows how the electron density varies with the production rate at 65,75 and $85 \mathrm{~km}$. These plots include the day, transition, and night periods for the observations on both 28 and 29 October. The dotted lines represent the square-law variation (Eq. (1)) with values of effective 


\begin{tabular}{|c|c|c|c|c|c|c|}
\hline $\begin{array}{l}\text { Height } \\
(\mathrm{km})\end{array}$ & \multicolumn{2}{|c|}{ Raw $\alpha_{\text {eff }}$} & \multicolumn{2}{|c|}{ Corrected $\alpha_{\mathrm{eff}}$} & \multicolumn{2}{|c|}{$\begin{array}{l}\text { Inter-quartile } \\
\text { range ratio }\end{array}$} \\
\hline & Day & Night & Day & Night & Day & Night \\
\hline 90 & \multicolumn{4}{|c|}{ 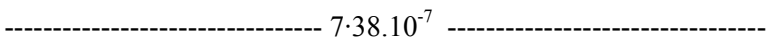 } & $2 \cdot 2$ & $2 \cdot 2$ \\
\hline 85 & \multicolumn{4}{|c|}{ 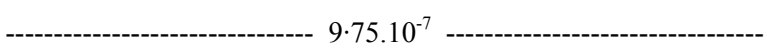 } & $2 \cdot 2$ & $2 \cdot 2$ \\
\hline 80 & \multicolumn{4}{|c|}{ 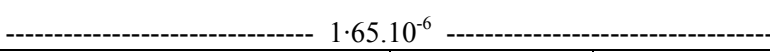 } & 1.9 & 1.9 \\
\hline 75 & $3 \cdot 04 \cdot 10^{-6}$ & $7 \cdot 01.10^{-6}$ & - & - & $2 \cdot 1$ & $1 \cdot 7$ \\
\hline 70 & $4 \cdot 48.10^{-6}$ & $7 \cdot 66.10^{-5}$ & $8 \cdot 96.10^{-6}$ & $3 \cdot 06.10^{-4}$ & $1 \cdot 7$ & $4 \cdot 0$ \\
\hline 65 & $5 \cdot 70.10^{-6}$ & $5 \cdot 05.10^{-4}$ & $1 \cdot 48.10^{-5}$ & $2 \cdot 02.10^{-3}$ & $1 \cdot 5$ & $3 \cdot 2$ \\
\hline 60 & $9 \cdot 77.10^{-6}$ & $3 \cdot 02.10^{-3}$ & $3 \cdot 13.10^{-5}$ & $1 \cdot 21.10^{-2}$ & $1 \cdot 3$ & $3 \cdot 8$ \\
\hline
\end{tabular}

Table 2. Estimates of effective recombination coefficient during the proton event of 28-29 October 2003. These are median values over the whole assembly of 5-min determinations, both raw and (where possible) corrected values.

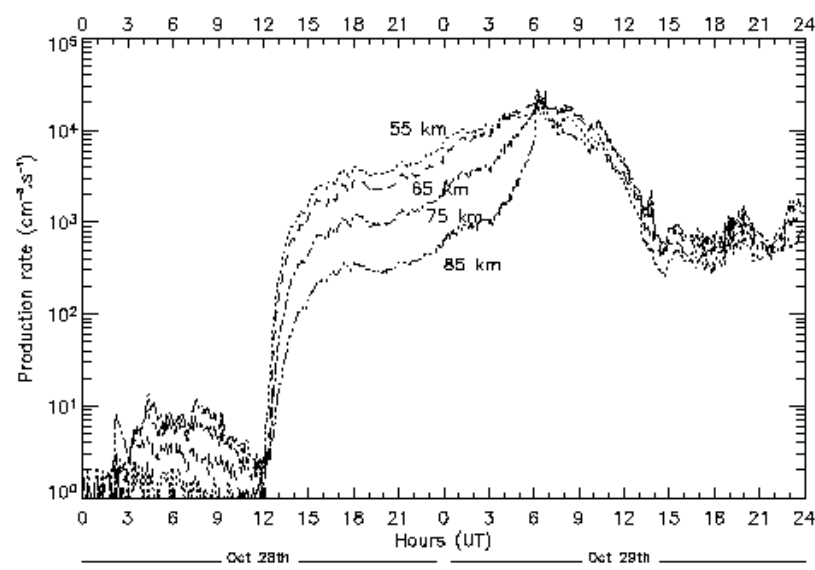

Fig. 7. Production rates at 55, 65, 75 and $85 \mathrm{~km}$ computed from proton spectra observed by GOES-11.

recombination coefficient $\left(\alpha_{e f f}\right)$ as parameter. Each plot shows a linear distribution extending over a range of $\mathrm{q}$ between about $10^{2}$ and $10^{4} \mathrm{~cm}^{-3} \mathrm{~s}^{-1}$, these points being for daytime. At each height Eq. (1) is obeyed over a variation of about two orders of magnitude in the production rate.

The clump which appears lower down the plot for $65 \mathrm{~km}$ contains the night-time points, the clumping being due to the lack of variation during the night periods on 28 and 29 October. Points between these two groups are for the evening day-night transitions. (The radar was not operating over sunrise on either day.) The diagrams for 60 and $70 \mathrm{~km}$ resemble that for $65 \mathrm{~km}$, though the amount of the day-night change decreases with increasing height. The diagram for $75 \mathrm{~km}$ shows only a small change of $\alpha_{e f f}$ over twilight. That for $85 \mathrm{~km}$ shows no twilight effect at all; the night and day points lie together and are consistent with a square-law relationship. The same is true at 80 and $90 \mathrm{~km}$, though the latter also shows some irregular enhancements of electron density which are probably due to ionization by auroral electrons at that altitude.

Table 2 lists the median values of the effective recombination coefficient from 60 to $90 \mathrm{~km}$ at $5 \mathrm{~km}$ intervals for 28 and
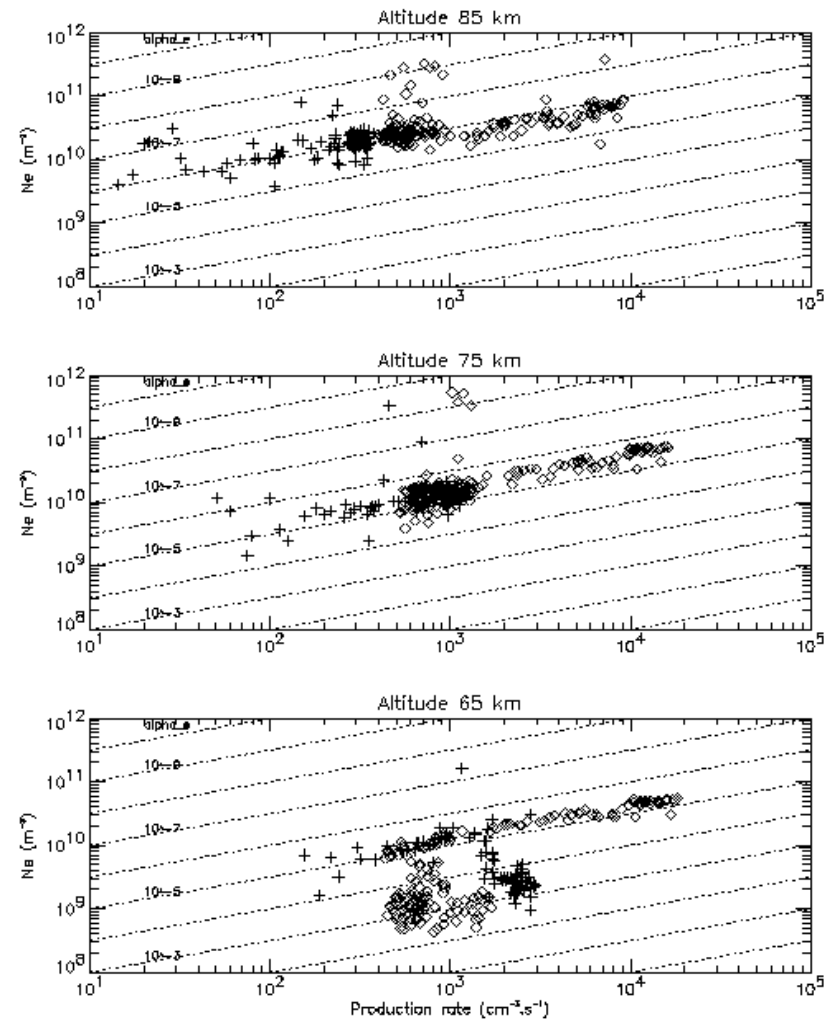

Fig. 8. Variation of electron density with production rate at 65,75 and $85 \mathrm{~km}$ : crosses for 28 October, diamonds for 29 October.

29 October (taken together) and for day and night. The interquartile range is typically a factor of 2 for day and a factor of 4 for night (all values being based on values of electron density averaged over $5 \mathrm{~min}$ ). The median values, each being taken over about 100 points, are therefore subject to statistical error of about $3.5 \%$ for day and $7 \%$ for night. At and above $80 \mathrm{~km}$, where there is no day-night variation, the statistical error will be about $2 \%$. However, the uncertainties due to the calibration of the radar, or, indeed, to real variations in the medium, are likely to be larger that this. In this analysis, data affected by obvious malfunction or other phenomena 
(for example, electron precipitation) have been discounted as far as possible. According to observations on the satellite Coronas-F over the polar cap (Panasyuk et al., 2004) a large increase in relativistic electron flux $(>1.5 \mathrm{MeV})$ occurred coincident with that in the proton flux. By reference to the computations of Gaines et al. (1995) it is estimated that the contribution to the production rate by the $\mathrm{MeV}$ electrons was no more than $1 \%$ of that due to the protons at the altitudes of interest.

Figure 9 plots our best estimates of the effective recombination coefficient for day and for night, showing also the inter-quartile range. Results from some other determinations by other methods are included for comparison. From 60 to $70 \mathrm{~km}$ in daytime there is good agreement with values recently obtained using an alternative method based on riometer data (Hargreaves, 2005). Between 60 and $80 \mathrm{~km}$ the daytime values are also within a factor of two of Gledhill's (1986) values, which were derived from a review of the literature and expressed as an exponential function of altitude. Gledhill's night values, however, do not agree well with the present results.

\subsection{Corrections}

There are, however, some corrections which should be applied. The electron density data from the radar are "raw data" based only on the intensity of the ion line in the incoherentscatter signal. At low electron density the Debye length, given by

$\lambda_{D}=\sqrt{\frac{\varepsilon_{0} k_{B} T}{N_{e} e^{2}}}$

becomes comparable with the wavelength of the radar, and then the raw electron density derived from the ion-line intensity is reduced as

$N_{e}^{\text {raw }}=\frac{2 N_{e}\left(1+2 \lambda_{-}\right)}{\left(1+\alpha^{2}\right)\left[1+\alpha^{2}+\left(1+2 \lambda_{-}\right) T_{e} / T_{i}\right]}$

where the parameter

$\alpha=4 \pi \lambda_{D} / \lambda_{R}$

$\lambda_{R}$ being the wavelength of the radar. $\lambda_{-}$is the ratio of negative ions to electrons, and $\mathrm{T}_{e}$ and $\mathrm{T}_{i}$ are the temperatures of the electrons and positive ions. For the EISCAT VHF radar, operating at $224 \mathrm{MHz}$, the Debye length effect is not important if the electron density is large compared to $8 \cdot 4 \cdot 10^{7} \mathrm{~m}^{-3}$. We can therefore neglect it in considering our present experimental data. However, the correction for negative ions becomes significant in the lower part of the D-region. Putting $\alpha \ll 1$ and $\mathrm{T}_{i}=\mathrm{T}_{e}$ for the $\mathrm{D}$-region gives

$N_{e}^{\text {raw }}=N_{e} \frac{\left(1+2 \lambda_{-}\right)}{\left(1+\lambda_{-}\right)}$.

The presence of negative ions may increase the signal as much as a factor of two, the effect of which would be to decrease our estimate of the effective recombination coefficient by a factor of four. Where this effect matters we should call a value derived using the raw electron density (i.e. one based on the intensity of the ion line) the "raw effective recombination coefficient".

As daytime values of $\lambda_{-}$, Rietveld and Collis (1993) give $0.8,1.3$ and 4.0 at 70,65 and $60 \mathrm{~km}$, respectively. The corresponding values of $N_{e}^{\text {raw }} / N_{e}$ are $1.4,1.6$ and 1.8 , and $\alpha_{e f f}^{r a w}$ should be multiplied by factors of 2.0, $2 \cdot 6$ and 3.2, respectively to get $\alpha_{\text {eff }}$ at those three heights. The negativeion/electron ratio at night is uncertain, but it is likely to be large compared to unity at heights of $70 \mathrm{~km}$ and below, implying that $\alpha_{e f f}^{r a w}$ should be multiplied by a factor of 4 to get night-time values of $\alpha_{e f f}$. On the evidence of Fig. 8 negative ions are unlikely to have much effect at and above $80 \mathrm{~km}$. Values corrected by these various factors are included in Table 2 and Fig. 9.

In the simple theory of recombination in the lower Dregion, the effective recombination coefficient, $\alpha_{e f f}$, may be written as

$\alpha_{e f f}=\left(1+\lambda_{-}\right)\left(\alpha_{e}+\lambda_{-} \alpha_{i}\right)$

the first term in the second bracket representing the loss of negative charge by electron recombination with positive ions, and the second term the loss via negative ions. The raw effective recombination coefficient is then expressed by

$\alpha_{e f f}^{r a w}=\alpha_{e}\left(1+\lambda_{-} \alpha_{i} / \alpha_{e}\right) \frac{\left(1+\lambda_{-}\right)^{3}}{\left(1+2 \lambda_{-}\right)^{2}}$

For the dominant reactions operating in the D-region, $\alpha_{e} \approx 5.10^{-7}$ and $\alpha_{i} \geq 5.10^{-6} \mathrm{~cm}^{3} \mathrm{~s}^{-1}$. If $\lambda_{-}$is small (say, above $75 \mathrm{~km}$ by day and above $80 \mathrm{~km}$ by night) the recombination is dominated by reactions between electrons and positive-ions, and

$\alpha_{\text {eff }}^{\text {raw }}=\alpha_{e}$

If $\lambda_{-}$is large (probably at and below $70 \mathrm{~km}$ by night),

$\alpha_{e f f}^{r a w}=\alpha_{i} \cdot \lambda_{-}^{2} / 4$

and the recombination is controlled by ionic reactions and the ion/electron ratio.

The transition during twilight is discussed in Sect. 5.

\subsection{Discussion}

\subsubsection{Negative-ion to electron ratios at night}

Rietveld and Collis (1993) estimated the negative-ion to electron ratio for daytime from measurements of the spectral width of the incoherent-scatter line, quoting values of 4.0 , $1 \cdot 3$, and $0 \cdot 8$ at 60,65 and $70 \mathrm{~km}$, respectively. From Eq. (7), assuming $\lambda_{-} \alpha_{i} \gg \alpha_{e}$, and using the values of $\alpha_{e f f}^{r a w}$ from Table 2 , we may estimate values of the recombination coefficient $\alpha_{i}$. The results are $1 \cdot 6.10^{-6}, 4 \cdot 7.10^{-6}$ and $6 \cdot 4.10^{-6}$, respectively. Although these values are within an order of magnitude, it seems unlikely that this coefficient decreases with altitude; if not constant, it would be expected to increase. 


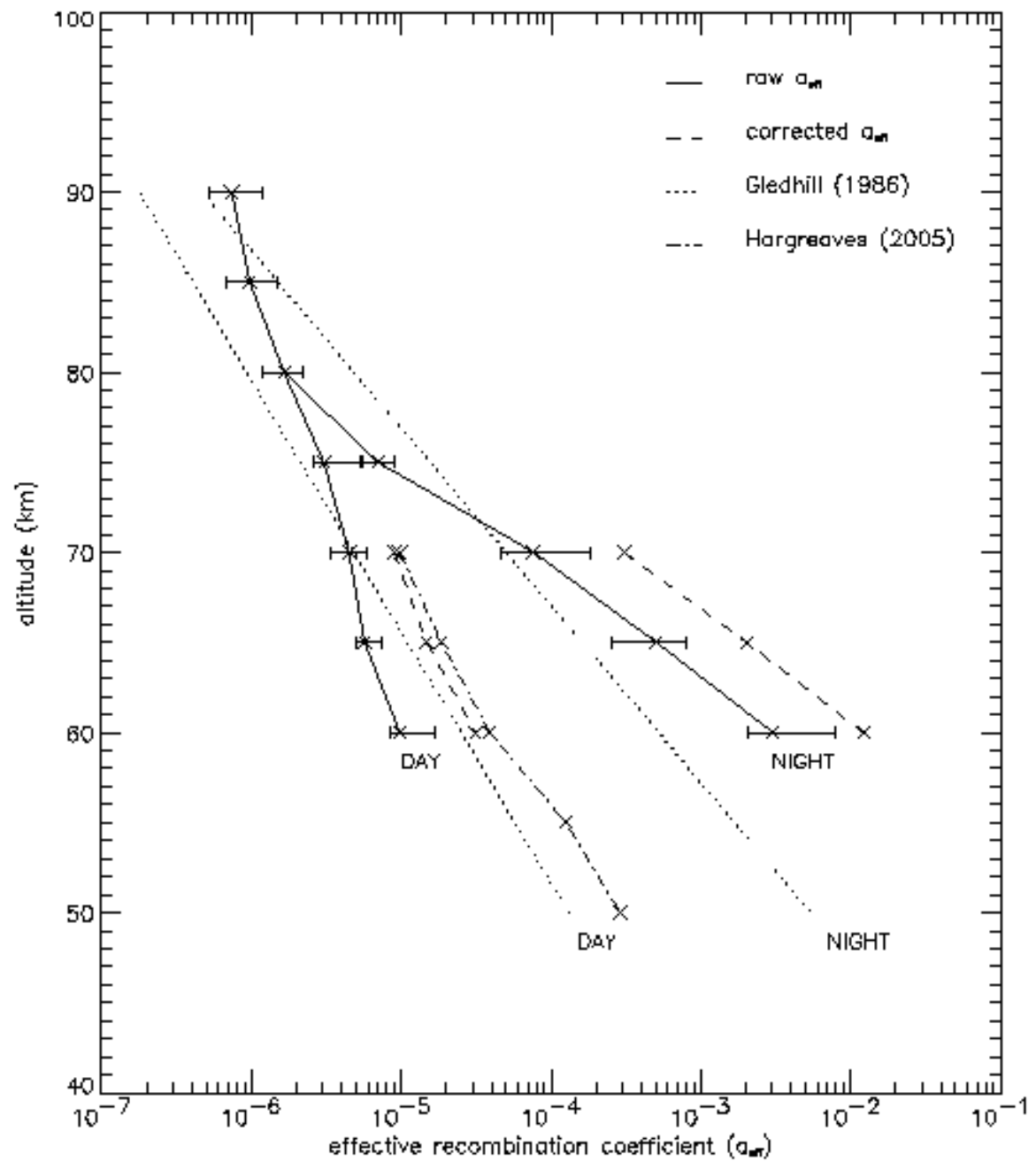

Fig. 9. Day and night profiles of effective recombination coefficient determined from the proton event of October 2003. Raw and corrected values (the latter not being required at and above $80 \mathrm{~km}$ ) are shown. The bars indicate the inter-quartile ranges. Values determined by Gledhill (1986) and by Hargreaves (2005) using different methods are included for comparison.

Therefore, for the purpose of the discussion, we will adopt the average of the values for 65 and $70 \mathrm{~km}$, giving $5 \cdot 6.10^{-6}$ which is also consistent with the generally accepted value of " $5.10^{-6}$ or greater". From Eq. (9) and our night values from Table 2, we may now estimate values of $\lambda_{-}$for night, assuming that the ionic recombination coefficient is the same by night as by day. The results for 60,65 and $70 \mathrm{~km}$ are respectively 48, 19 and 7.4. If a larger value is assumed for $\alpha_{i}$, the deduced values of $\lambda_{-}$will be smaller.

Over the range $60-70 \mathrm{~km}$ the derived night-time values of $\lambda_{-}$increase by a factor of about 2.55 for each $5 \mathrm{~km}$ decrease in height, implying an exponential variation with a scale height of about $5.3 \mathrm{~km}$, which is approximately the scale height of the neutral atmosphere in the mesosphere. This result, which does not depend on the value of $\alpha_{i}$, is consistent with the night-time production of negative ions from electrons being due to 3-body attachment and their loss to collisional detachment.

\subsubsection{The form of the recombination law}

In the simple continuity equation of D-region aeronomy, expressed by Eq. (1), the electron production rate and the equilibrium electron density are related by a square law. Despite its common usage, such a law is a gross simplification of the chemistry of the D-region which is actually quite complicated, involving both simple and complex (or cluster) ions of both signs. To attempt to represent the chemistry more accurately, chemical models of various levels of sophistication have been developed. One of the first was the 6-ion model of Mitra and Rowe (1972) in which the complex ions were represented as two single species, one positive and one negative. More recent models (Burns et al., 1991; Kirkwood and Osepian, 1995), which include more individual reactions, are considerably more elaborate. The first of those, the "Sodankylä model", included the reactions between 24 positive and 11 negative ions (and has since been elaborated further (Turunen et al., 1996)). 


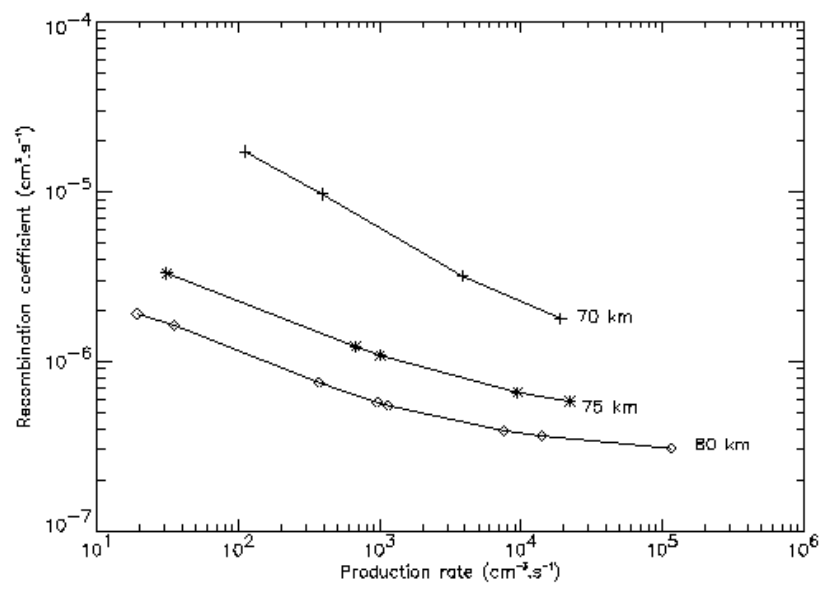

Fig. 10. Values of effective recombination coefficient computed from the Sodankylä chemical model of the D-region. (After Hargreaves and Howarth, previously unpublished)

When these models are used to compute electron densities from ion production rates, the continuity law that they produce deviates from the square law at some heights and over some ranges of electron density. The effect may be seen in the results of Kirkwood and Osepian (1995) and of del Pozo et al. (1997), for example. The implication is that the effective recombination coefficient is not exactly constant but varies with the production rate. Figure 10 (which is based on computations using the Sodankylä model) illustrates the point. Computed values of effective recombination coefficient are shown over a range of production rates for several altitudes, according to which the effective recombination coefficient at 70, 75 and $80 \mathrm{~km}$ decreases as the production rate increases between $10^{2}$ and $10^{4} \mathrm{~cm}^{-3} \mathrm{~s}^{-1}$. It does tend to a constant value at the greater levels of production rate.

Considering the large number of interactions involved in the D-region, deviation from a simple continuity law should, perhaps, not be surprising. However, our present experimental results seem to show that the square law is actually obeyed remarkably closely if the production rate is in the range $10^{2}$ to $10^{4} \mathrm{~cm}^{-3} \mathrm{~s}^{-1}$, and this must cast doubt on the accuracy of the computational models. In those models the relative concentration of simple and cluster ions varies with the ion production rate. The positive cluster ions (such as $\mathrm{H}^{+}\left(\mathrm{H}_{2} \mathrm{O}\right)_{n}$ and $\left.\mathrm{NO}^{+}\left(\mathrm{H}_{2} \mathrm{O}\right)_{n}\right)$, are relatively more numerous than the simple ions (such as $\mathrm{NO}^{+}$) at the lower production rates but become relatively less numerous as the production rate increases. The cluster ions, being physically larger, recombine more rapidly than the simple ions with electrons, and thus the models predict that the effective recombination rate decreases as the production rate increases. The discrepancy with experiment suggests that the complex ions have less effect on the overall electron loss rate than has been supposed.
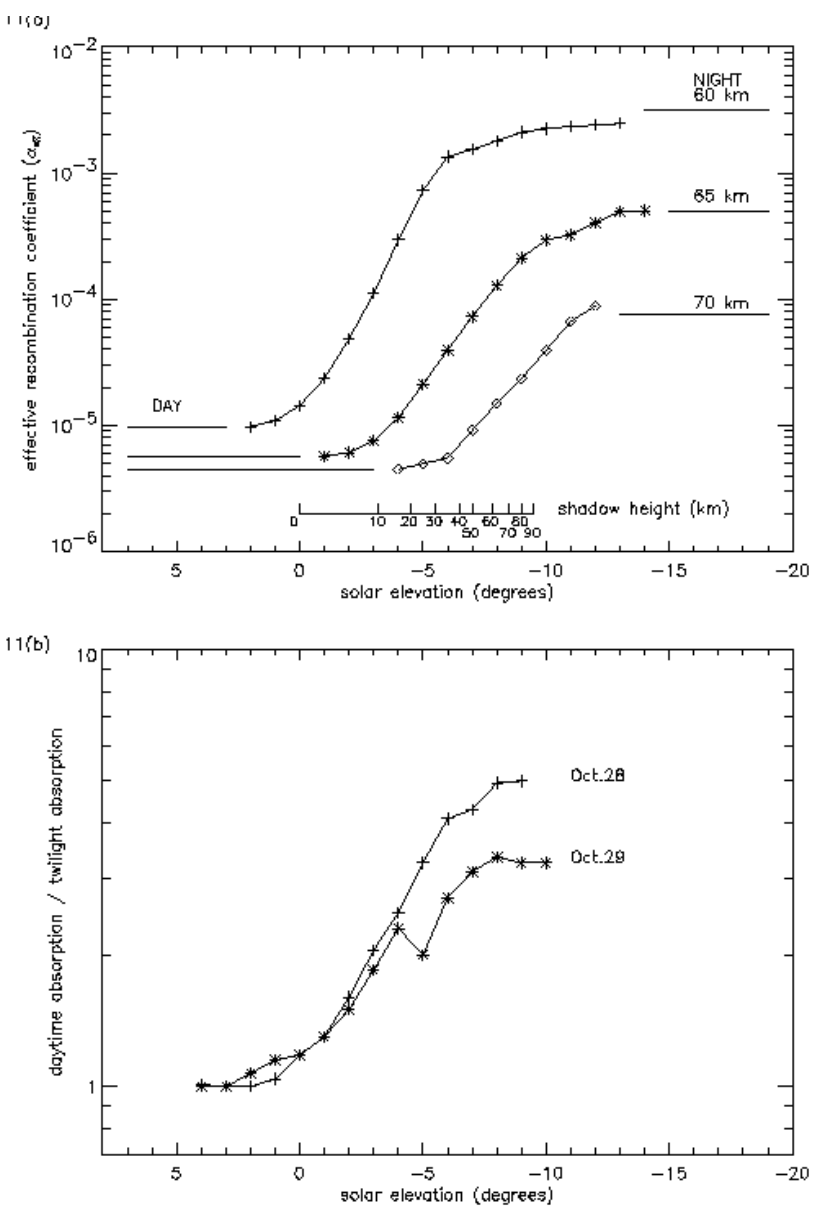

Fig. 11. Changes during evening twilight as a function of solar elevation. (a) Effective recombination coefficient (uncorrected) at 60,65 and $70 \mathrm{~km}$, based on the observations of 28-29 October. The median day and night values have been added. (b) Change of $38.2 \mathrm{MHz}$ radio absorpion at Kilpisjärvi for 28-29 October separately. Since the absorption reduces during twilight the plot shows the ratio (daytime value)/(twilight value). The values have been corrected for the computed variation of production rate at $55 \mathrm{~km}$.

\section{The sunset twilight period}

The nature of the transition between day and night conditions is an intriguing problem of the D-region. The timing and pattern of the change is unlike that of the main ionospheric layers, occurring rather sharply over a short period just before ground sunrise and during a period following ground sunset. This phenomenon is well known in VLF propagation (Bracewell and Bain, 1952; Hargreaves, 1962) as well as in polar-cap absorption. Clearly, the basic mechanism must be photochemical, but the controlling agent cannot be a solar radiation that is strongly absorbed in the upper atmosphere, which rules out X-rays and extreme ultra-violet (EUV). Since the change occurs while the Sun is at very low elevation and mainly while it is actually below the horizon, attention turned to visible light or some other radiation that was only weakly absorbed in the atmosphere. Attempts to 
explain the observations include the hypothesis of a screening layer which fully absorbs the effective radiation below some altitude but not above it. The question is discussed by Adams and Megill (1967) and by Reid (1974) among others.

In Fig. 11 we show the change in the effective recombination coefficient (as defined by Eq. (1)) at 60,65 and $70 \mathrm{~km}$ during sunset twilight, taking account of the observations on both 28 and 29 October. The variation of the radio absorption observed by the riometer at Kilpisjärvi (see Fig. 3) on these days is also shown. The latter will of course be affected by the change in proton flux as well as by the chemistry, and therefore the absorption has been corrected to a constant production rate at $55 \mathrm{~km}$ (Fig. 7). The pattern of absorption is most similar to that of the effective recombination coefficient at $60 \mathrm{~km}$ in Fig. 11(a).

Collis and Rietveld (1990), in their study of the PCAs of October 1989, reported that the timing of the day/night transition depended on the altitude being observed. In the evening the change was found to be delayed linearly with increasing altitude, the solar depression angle at the onset of the transition increasing by about $4.5^{\circ}$ for each $10 \mathrm{~km}$ increase in altitude. The present results for October 2003 confirm this effect, the delay here being equivalent to about $6^{\circ}$ of solar depression per $10 \mathrm{~km}$ of altitude.

Figure 11 also shows how the altitude of the Earth's shadow overhead varies with the solar depression angle. Although the Sun is below the horizon at ground level during most of the transition, the layers of the D-region are still sunlit when the twilight change begins. The 60 and $65 \mathrm{~km}$ levels also remain sunlit throughout all or most of the change. (This is the kind of observation which suggests the existence of a screening layer.) However, since the solar depression angle needs to increase by less than one degree to lift the shadow by $10 \mathrm{~km}$ at D-region heights, it is doubtful whether the observed delays can be explained in terms of the movement of the Earth's shadow, with or without a screening layer.

It is clear from the discussion of Sect. 4.2 that the changes shown in Fig. 11 are the effects of a changing negativeion/electron ratio during twilight, as an increasing fraction of the negative charge moves from electrons to negative ions. If we assume that $\lambda_{-} . \alpha_{i} \gg \alpha_{e}$ and take a value $\left(5 \cdot 6.10^{-6}\right)$ for $\alpha_{i}$, we may estimate how $\lambda_{-}$changes during twilight. Equation (9) applies over most of the transition but Eq. (7) has to be used if $\lambda_{-}$is smaller than about 5 . The result is shown for 60,65 and $70 \mathrm{~km}$ in Fig. 12, on which the typical day and night values are also marked.

\section{Conclusions}

- Empirical relations have been derived between proton flux and electron density during the PCA of 28-29 October 2003. It is found that the flux in the energy band $4-9 \mathrm{MeV}$ has greatest control over the range $70-85 \mathrm{~km}$. The most effective bands are $9-40 \mathrm{MeV}$ at $65 \mathrm{~km}$ and $40-80 \mathrm{MeV}$ at $60 \mathrm{~km}$;

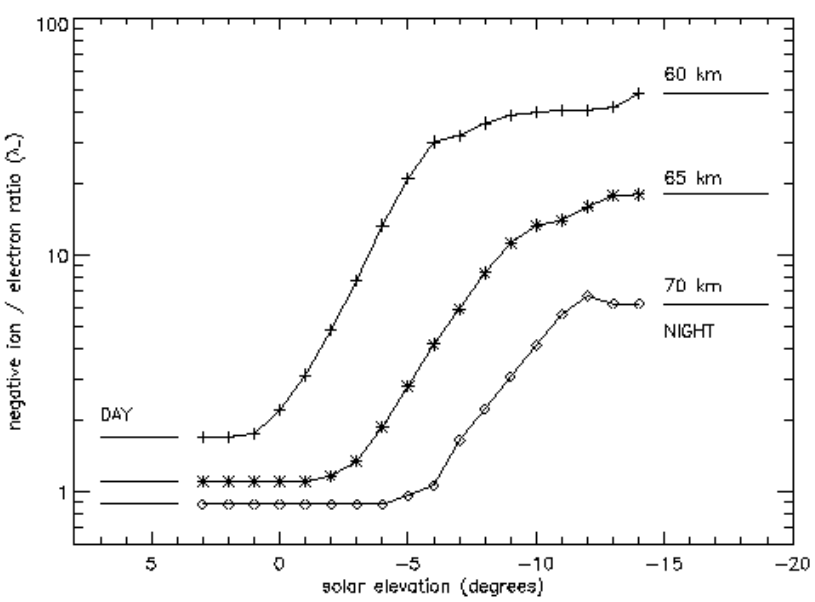

Fig. 12. Estimated variation of the concentration ratio of negative ions to electrons during evening twilight.

- Values of effective recombination coefficient have been determined for day and night. There is no day-night change at or above $80 \mathrm{~km}$, but below that level the day-night change becomes progressively larger with decreasing altitude. The height variation of the coefficient at night is consistent with negative-ion production by a 3-body process and loss by collisional detachment;

- The observations do not support other than a square law of recombination. There is no evidence of the deviation from the square law which is predicted by chemical models;

- The timing of the sunset transition is such that the solar depression angle at the onset of the effect varies linearly with the height considered, supporting the earlier report by Collis and Rietveld (1990). It does not appear feasible to explain the timing of the twilight effect in terms of a single "screening layer". Values for the negativeion/electron ratio are estimated for night and during the sunset change.

Acknowledgements. We thank H. H. Sauer for providing the GOES proton fluxes and G. C. Reid for the use of the program for computing production rates, both of the National Oceanic and Atmospheric Administration, Boulder, Colorado. We also thank the EISCAT Group at the Rutherford Appleton Laboratory, Chilton, for supplying the EISCAT data. The Finnish chain of riometers is operated by the Sodankylä Geophysical Observatory, and the Kilpisjärvi imaging riometer jointly with the University of Lancaster, England.

Topical Editor M. Pinnock thanks A. Shirochkov and another referee for their help in evaluating this paper. 


\section{References}

Adams, G. W. and Megill, J. R.: A two-ion D-region model for polar cap absorption events, Planet. Space Sci., 15, 1111-1130, 1967.

Bailey, D. K.: Abnormal ionization in the lower ionosphere associated with cosmic-ray enhancements. Proc. IRE 47, 255-266, 1959.

Bailey, D. K.: Polar-cap absorption., Planet. Space Sci., 12, 495541, 1964.

Birch, M. J., Hargreaves, J. K., Senior, A., and Bromage, B. J. I.: Variations in cutoff latitude during selected solar energetic proton events, J. Geophys. Res., 110(A7),A07221, 2005.

Bracewell, R. N. and Bain, W. C.: An explanation of radio propagation at $16 \mathrm{kc} / \mathrm{s}$ in terms of two layers below E layer, J. Atmos. Terr. Phys., 2, 216-225, 1952.

Burns, C. J., Turunen, E., Matveinen, H., Ranta, H. and Hargreaves, J. K.: Chemical modelling of the quiet summer D- and E-regions using EISCAT electron density profiles, J. Atmos. Terr. Phys., 53, 115-135, 1991.

Collis, P. N. and Rietveld, M. T.: Mesospheric observations with the EISCAT UHF radar during polar cap absorption events: 1 . Electron densities and negative ions, Ann. Geophys., 8, 809-824, 1990.

del Pozo, C. F., Hargreaves, J. K., and Aylward, A. D.: Ion composition and effective ion recombination rate in the nighttime auroral lower ionosphere. J. Atmos. Solar-Terrestrial Phys. 59, 1919-1934, 1997.

Gaines, E. E., Chenette, D. L., Imhof, U. L., Jackman, C. H., and Winningham, J. D.: Relativistic electron fluxes in May 1992 and their effect on the middle atmosphere, J. Geophys. Res., 100, 1027-1033, 1995.

Gledhill, J. A.: The effective recombination coefficient of electrons in the ionosphere between 50 and $150 \mathrm{~km}$. Radio Sci., 21, 399408, 1986.

Hargreaves, J. K.: The behaviour of the lower ionosphere near sunrise, J. Atmos. Terr. Phys., 24, 1-7, 1962.

Hargreaves, J. K., Ranta, A., Ranta., H., Turunen, E., and Turunen., T.: Observations of the polar cap absorption event of Februaury 1984 by the EISCAT incoherent scatter radar, Planet. Space Sci., 35, 947-958, 1987.

Hargreaves, J. K.: A new method of studying the relation between ionization rates and radio-wave absorption in polar-cap absorption events., Ann. Geophys., 23, 359-369, 2005,

SRef-ID: 1432-0576/ag/2005-23-359.
Hultqvist, B.: Polar cap absorption and ground level effects. Solar flares and Space Research (Eds.) de Jager, C. and Svestka, Z. 215-257, Amsterdam, 1969.

Kirkwood, S. and Osepian, A.: Qualitative studies of energetic particle precipitation using incoherent scatter radar, J. Geomag. Geoelectr., 47, 783-799, 1995.

Mitra, A. P. and Rowe, J. N.: Ionospheric effects of solar flares - VI. Changes in D-region ion chemistry during solar flares, J. Atmos. Terr. Phys., 34, 795-806, 1972.

Panasyuk, M. I., Kuznetsov, S. N., Lazutin, L. L.: Magnetic Storms in October 2003, Cosmic Research, 42, 5, 489-535, 2004.

Penman, J. M., Hargreaves, J. K., and McIlwain, C. E.: The relations between 10 to $80 \mathrm{keV}$ electron precipitation observed at geosynchronous orbit and auroral radio absorption observed with riometers. Planet. Space Sci. 27, 445-451, 1979.

Potemra, T. A.: The empirical connection of riometer absorption to solar protons during PCA events, Radio Sci., 7, 571-577, 1972.

Reagan, J. B. and Watt, T. M.: Simultaneous satellite and radar studies of the D-region ionosphere during the intense solar particle event of August 1972, J. Geophys. Res., 81, 4579-4596, 1976.

Reid, G. C.: Current problems in polar-cap absorption. In Intercorrelated Satellite Observations related to Solar Events, (Eds.) Manno, V. and Page, D. E. D. Reidel, Dortrecht, 319-334, 1970.

Reid, G. C.: Polar-cap absorption - observations and theory. Fundamentals of Cosmic Physics 1, 167-200, 1974.

Reid, G. C.: Solar energetic particles and their effects on the terrestrial environment. In Physics of the Sun, Vol III, Astrophysics and Solar-Terrestrial Relations, 251, (Eds.) Sturrock, P. A., Holzer, T. E., Mihalas, D. M., and Ulrich, R. D., D. Reidel Publishing Company, Dordrecht, 1986.

Reid, G. C., Soloman, S., and Garcia, R. R.: Response of the middle atmosphere to the solar proton events of August-December 1985, Geophys. Res. Lett., 18, 1019-1022, 1991.

Rietveld, M. T. and Collis, P. N.: Mesospheric observations with the EISCAT UHF radar during polar cap absorption events: 2. Spectral measurements. Ann. Geophys., 11, 797-808, 1993.

Rishbeth, H. and Williams, P. J. S.: The EISCAT ionospheric radar: the system and its early results. Q. Jour. R. Astr. Soc. 26, 478$512,1985$.

Turunen, E., Matveinen, H., Tolvanen, J., and Ranta, H.: D-region ion chemistry model, STEP Handbook of Ionospheric Models, (Ed.) Schunk, R. W., 1-25, SCOSTEP Secretariat, Boulder, Colorado, USA, 1996. 